\title{
Зависимость проводимости слоев пористого кремния от направления переноса носителей заряда
}

\author{
(C) Е.А. Гусева, Е.А. Форш \\ Московский автомобильно-дорожный государственный технический университет, \\ 125319 Москва, Россия \\ ฯ E-mail: forsh_kate@list.ru \\ Поступила в Редакцию 18 октября 2018 г. \\ В окончательной редакции 28 февраля 2019 г. \\ Принята к публикации 5 марта 2019 г.
}

\begin{abstract}
Представлено исследование механизмов переноса носителей заряда в слоях мезопористого кремния для случаев переноса вдоль поверхности слоя (перпендикулярно кремниевым колоннам) и перпендикулярно поверхности слоя (вдоль кремниевых колонн). Установлено, что проводимость, измеряемая вдоль поверхности слоя, значительно ниже проводимости, измеряемой перпендикулярно поверхности. Из анализа температурных и частотных зависимостей проводимости сделан вывод о различных механизмах переноса носителей заряда в рассматриваемых случаях (вдоль и перпендикулярно поверхности).
\end{abstract}

Ключевые слова: наноструктурированный кремний, потенциальные барьеры, механизм переноса носителй заряда, температурные зависимости проводимости, частотные зависимости проводимости.

DOI: 10.21883/FTP.2019.07.47873.9007

\section{1. Введение}

Одним из наиболее быстро развивающихся в настоящее время направлений современной физики является изучение оптических, электрических и фотоэлектрических свойств полупроводниковых низкоразмерных систем, в том числе ансамблей связанных нанокристаллов. Пористый кремний (ПК) является подходящим объектом для данных исследований, поскольку прост в получении и позволяет легко изменять (в зависимости от условий получения) свои структурные свойства, такие как форма, размер, положение кремниевых нанокристаллов и др. Изучение полупроводниковых нанокристаллов и квантовых точек, состоящих из кремния, актуально еще и потому, что данный химический элемент составляет основу современной полупроводниковой электроники. В литературе широко обсуждаются возможности создания светоизлучающих диодов, одноэлектронных транзисторов, устройств памяти и газовых сенсоров на основе кремниевых нанокристаллов [1-7]. Однако, несмотря на большое число написанных к настоящему времени работ, электрофизические свойства наноструктурированного кремния изучены еще далеко не в полной мере.

К настоящему времени в литературе подробно проанализированы механизмы переноса носителей заряда в ПК с малым (< 5 нм) размером нанокристаллов, в котором за счет квантово-размерного эффекта образуются локализованные уровни энергии в кремниевых нанокристаллах. В этом случае, как правило, предполагают прыжковый механизм проводимости с учетом фрактальной структуры ПК [8]. В то же время электронный перенос в образцах мезопористого кремния (мезо-ПК) с размером нанокристаллов большим $10 \mathrm{Hм}$, в которых квантово-размерный эффект пренебрежимо мал, изучен в гораздо меньшей степени. Показано, что в этом случае происходит перенос носителей заряда по делокализованным состояниям $[9,10]$. Кроме того, в образцах мезо-ПК отчетливо наблюдается структурная анизотропия формы нанокристаллов [11-15], а именно кремниевые нанокристаллы имеют форму цилиндров (колонн), расположенных перпендикулярно поверхности образца. Однако в литературе отсутствуют данные сравнения механизмов переноса носителей заряда в мезо-ПК вдоль колонн и перпендикулярно им, хотя подобного рода исследования должны способствовать лучшему пониманию механизмов транспорта носителей в наноструктурированных материалах на основе кремния.

В данной работе проведено сравнение проводимости мезо-ПК в зависимости от направления переноса носителей заряда.

\section{2. Методика эксперимента}

Исследованные в работе слои ПК получались методом электрохимического травления монокристаллических пластин $p^{+}-\mathrm{Si}: \mathrm{B}$ (с удельным сопротивлением 1-5 мОм·см) и ориентацией поверхности (100) в растворе HF (48\%) с этанолом в соотношении 1:1. Электрохимическое травление образцов происходило при плотности тока $J=40 \mathrm{MA} / \mathrm{cm}^{2}$ в течение $t=30$ мин. Отделение слоя ПК от подложки осуществлялось по окончании процесса порообразования кратковременным $\left(\sim 2\right.$ c) увеличением плотности тока до $600 \mathrm{MA} / \mathrm{cm}^{2}$. Толщина отделенных слоев пористого кремния равнялась $\sim 70$ мкм. Известно [4], что полученный указанным выше способом ПК имеет пористость около 60\% и состоит из кристаллов кремния размером 10-100 нм. Образцы ПК, полученные в результате травления монокристаллических пластин кремния с ориентацией по- 
верхности (100), состоят из цилиндрических колонн, расположенных перпендикулярно поверхности образца.

Для измерения электрических характеристик на поверхность образцов напылялись алюминиевые контакты в двух различных конфигурациях: „сандвич“ и „планар“. В случае конфигурации типа „сандвич“ на поверхность слоя ПК наносился алюминиевый контакт площадью $\sim 1$ мм² $^{2}$ а нижним электродом служила сильно легированная подложка $c$-Si. Такое расположение контактов позволяло исследовать перенос носителей заряда вдоль кремниевых колонн. В случае конфигурации типа „планар“ алюминиевые контакты напылялись на поверхность слоя ПК. Расстояние между контактами при этом составляло 0.2 мм. В данном случае транспорт носителей заряда происходил перпендикулярно кремниевым колоннам.

Перед выполнением измерений образец ПК помещался в азотный криостат, который откачивался до давления $\sim 10^{-4}$ Торр. После этого проводился температурный отжиг при $T=370 \mathrm{~K}$ в течение 30 мин. В результате этого отмечалось увеличение проводимости на 1-2 порядка по сравнению с образцами находящимися на воздухе. Предполагается, что это связано с десорбцией молекул воды с внутренней поверхности ПК. Охлаждение образца происходило с помощью жидкого азота. Температура регистрировалась посредством термопары, находящейся в непосредственной близости от образца. Измерения проводились в диапазоне температур от 300 до $360 \mathrm{~K}$.

Проводимость слоев ПК измерялась с помощью пикоамперметра Keithley 6487, обладающего высокой чувствительностью. Напряжение на образец подавалось с источника, встроенного в пикоамперметр.

Измерения зависимости проводимости от частоты переменного сигнала проводились с помощью импедансанализатора НР 4192А в интервале частот от 50Гц до 13 МГц.

\section{3. Экспериментальные результаты и их обсуждение}

На рис. 1 представлены вольт-амперные характеристики (BAX) слоев ПК, измеренные при комнатной температуре на постоянном токе. Аналогичные зависимости были получены для всех исследованных в работе температур. Измерения проводились при двух конфигурациях контактов - „сандвич“ и „планар“. Из данных зависимостей видно, что ВАХ образцов являются симметричными относительно полярности приложенного напряжения. Видно также, что вольт-амперные характеристики для обоих исследованных направлений являются нелинейными.

Нелинейность ВАХ может быть связана с наличием в исследованных слоях потенциальных барьеров. В случае „планара“ барьеры могут существовать как на границе образец-контакт (Al/ПК), так и на границе самих нанокристаллов. В случае ориентации контактов типа „сандвич“ нелинейность, по-видимому, вызвана неомичностью контактов $\mathrm{Al} /$ ПК и ПК $/ c-\mathrm{Si}$, поскольку в этом случае носители могут двигаться вдоль колонн и не испытывать влияния потенциальных барьеров, находящихся на их границах.

Температурные зависимости проводимости $(\sigma)$ ПК, измеренной на постоянном токе, для указанных выше случаев ориентации контактов показаны на рис. 2. Из рисунка видно, что значение проводимости в „сандвиче“ больше, чем в „планаре“ во всем диапазоне исследованных температур, а зависимости $\sigma(T)$ имеют характер, близкий к активационному, т.е. описываются уравнением

$$
\sigma=\sigma_{0} \exp \left(-\frac{E_{\alpha}}{k T}\right),
$$

где $\sigma_{0}-$ предэкспоненциальный множитель, $E_{a}-$ энергия активации, $k$ - постоянная Больцмана. Энергия

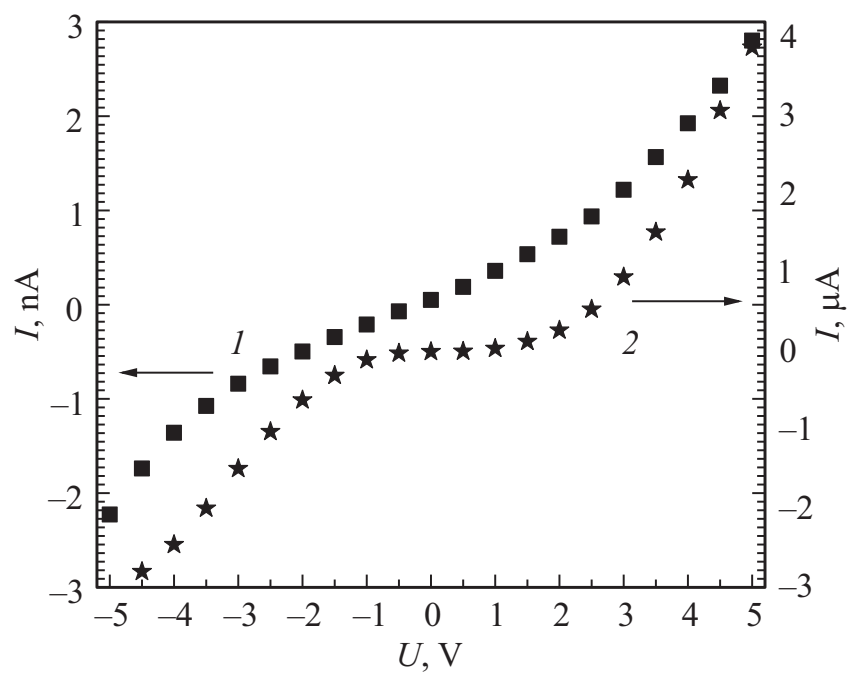

Рис. 1. Вольт-амперные характеристики ПК с ориентацией контактов типа „планар“ (1) и „сандвич“ (2).

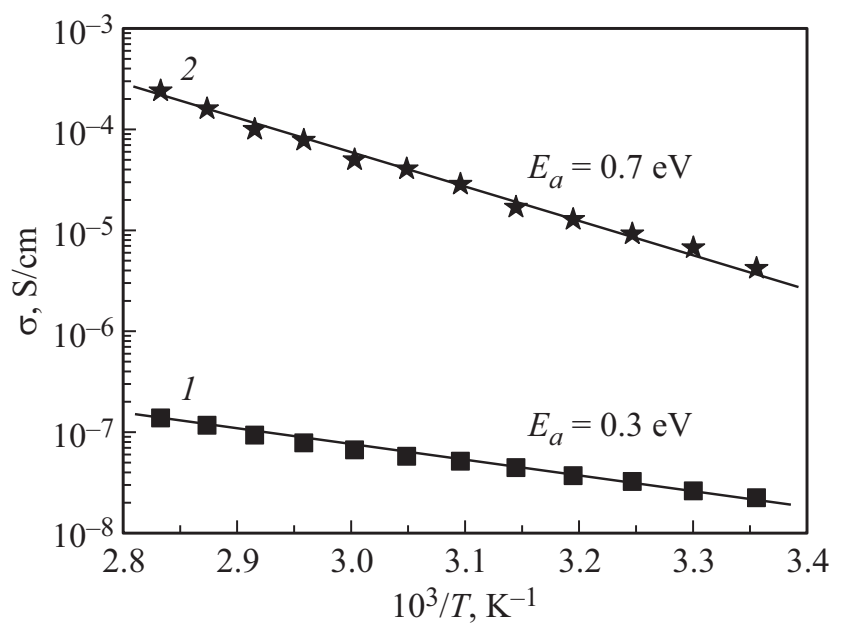

Рис. 2. Температурные зависимости проводимости ПК для ориентации контактов типа „планар“ (1) и „сандвич“ (2). К образцу (и для одной, и для другой ориентации контактов) приложено напряжение $U=5 \mathrm{~B}$. На рисунке также приведены значения энергий активации проводимости. 


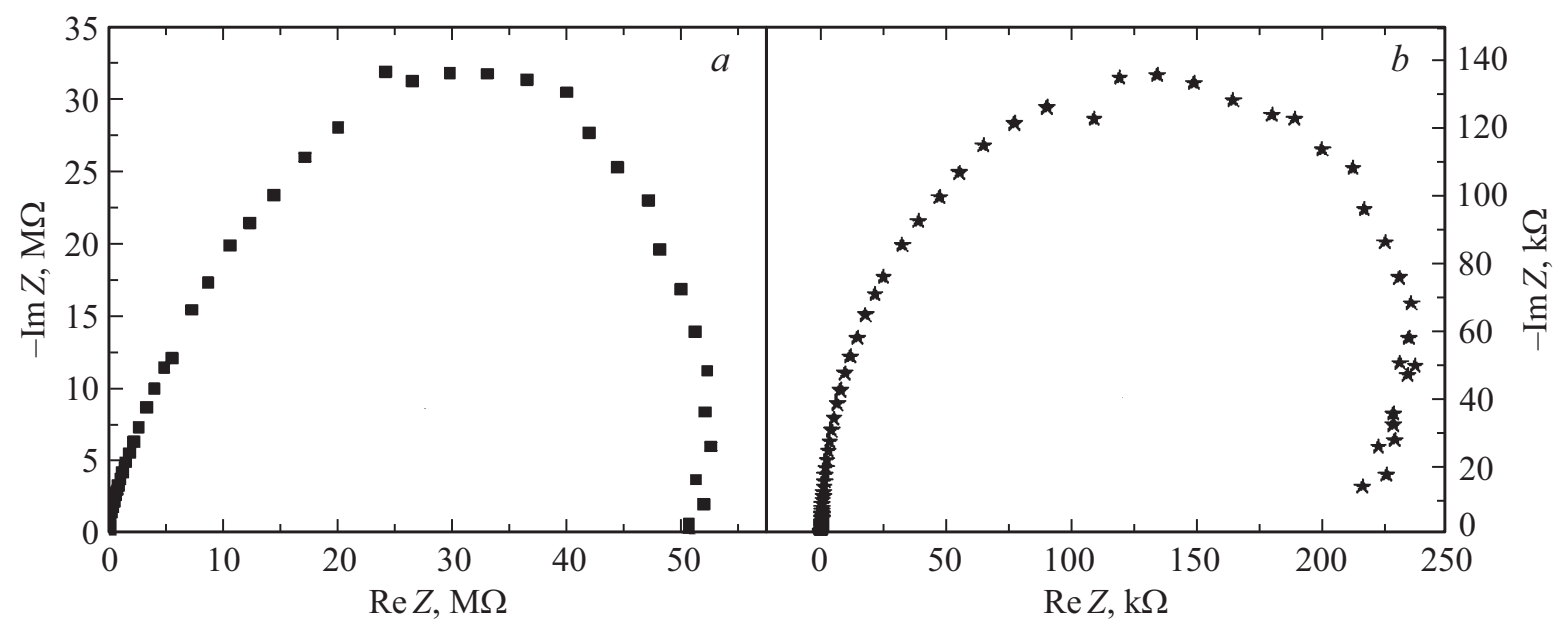

Рис. 3. Зависимости мнимой части $(-\operatorname{Im} Z)$ от действительной части $(\operatorname{Re} Z)$ импеданса, полученные при комнатной температуре, для образцов ПК в случае расположения контактов типа „планар“ $(a)$ и „сандвич“ $(b)$.

активации $E_{a}$ может быть записана в виде [16-18]

$$
E_{a}=\left(E_{c}-E_{F}\right)_{0}+E_{b},
$$

где $\left(E_{c}-E_{F}\right)_{0}$ - значение, получающееся аппроксимацией температурной зависимости $\left(E_{c}-E_{F}\right)$ к нулевой температуре, а $E_{b}$ - эффективная энергетическая высота существующих в структуре потенциальных барьеров. В случае переноса дырок вдоль колонн (т.е. при конфигурации контактов типа „сандвич“) величина $E_{b}$ определяется потенциальными барьерами на границах $\mathrm{Al} /$ ПК и ПК/c-Si. В то же время в случае „Планара“ эффективная высота потенциальных барьеров складывается из высот потенциальных барьеров между колоннами и потенциального барьера $\mathrm{Al} /$ ПК. Очевидно, что значение $\left(E_{c}-E_{F}\right)_{0}$ не зависит от расположения контактов. Таким образом, различие в значениях энергии активации температурных зависимостей проводимости, измеренных вдоль и поперек слоя ПК, связано с разным значением $E_{b}$. По-видимому, на границе ПК/c-Si существует достаточно высокий потенциальный барьер, который и приводит к значительно большей энергии активации в случае расположения контактов типа „сандвич“.

Для дальнейшего выяснения особенностей переноса носителей заряда вдоль каждого из указанных направлений были проведены исследования частотных зависимостей импеданса $(Z)$. На рис. 3 показаны зависимости мнимой части импеданса $(-\operatorname{Im} Z)$ от действительной $(\operatorname{Re} Z)$, измеренные при комнатной температуре, для переноса носителей заряда вдоль поверхности слоя и перпендикулярно ей.

Возможная эквивалентная схема, позволяющая описать представленные зависимости мнимой части импеданса от действительной для каждой ориентации контактов приведена на рис. 4. Однако физический смысл приведенных на эквивалентной схеме элементов различен для конфигураций „планар“ и „сандвич“. В случае конфигурации „планар“ $R_{c}$ и $C_{c}-$ сопротивление и емкость потенциальных барьеров между нанокристаллами

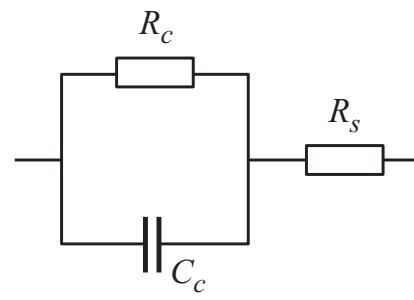

Рис. 4. Эквивалентная электрическая схема исследованных образцов.

и потенциального барьера на границе $\mathrm{Al} / \Pi$ П, а $R_{s}-$ сопротивление кремниевых колонн. В случае же конфигурации „сандвич“ $R_{s}$ - по-прежнему сопротивление кремниевых колонн, однако $R_{c}$ и $C_{c}-$ сопротивление и емкость потенциальных барьеров на границах $\mathrm{Al} /$ ПК и $\Pi К / c-\mathrm{Si}$.

Для предложенной эквивалентной схемы можно рассчитать адмиттанс $Y=1 / Z$ :

$Y=\frac{R_{c}+R_{s}+\omega^{2} R_{c}^{2} C_{c}^{2} R_{s}}{\left(R_{c}+R_{S}\right)^{2}+\omega^{2} R_{c}^{2} R_{s}^{2} C_{c}^{2}}+i \omega \frac{R_{c}^{2} C_{c}}{\left(R_{c}+R_{S}\right)^{2}+\omega^{2} R_{c}^{2} R_{s}^{2} C_{c}^{2}}$,

где $\omega=2 \pi f-$ циклическая частота, $i-$ мнимая единица $[19,20]$.

В соответствии с последней формулой в предположении, что $R_{s} \ll R_{c}$, легко выделяются три приведенных далее характерных участка на зависимости реальной части адмиттанса $(\operatorname{Re} Y)$ от $\omega$.

1. В области частот, удовлетворяющих неравенству $\omega^{2} R_{c} R_{s} C_{c}^{2} \ll 1$, реальная часть аддмитанса

$$
\operatorname{Re} Y=\frac{1}{R_{c}}
$$

2. Для частот, заданных соотношениями

$$
\omega^{2} R_{c} R_{s} C_{c}^{2} \gg 1 ; \quad \omega^{2} R_{s}^{2} C_{c}^{2} \ll 1,
$$




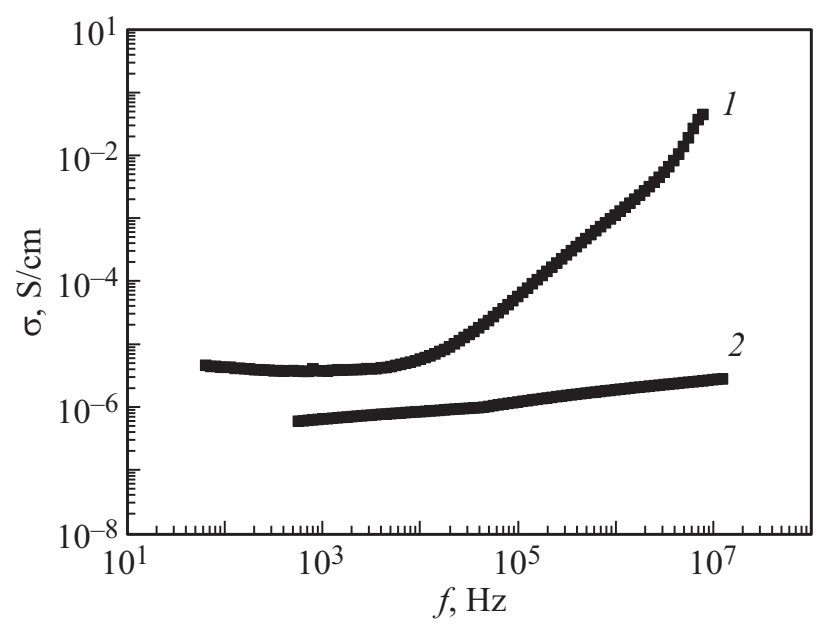

Pис. 5. Частотные зависимости проводимости ПК для ориентации контактов типа „сандвич“ (1) и „планар“ (2).

реальная часть адмиттанса

$$
\operatorname{Re} Y=\omega^{2} R_{s} C_{c}^{2} .
$$

3. И наконец, при высоких частотах, определяемых условием

$$
\omega^{2} R_{s}^{2} C_{c}^{2} \gg 1
$$

реальная часть адмиттанса

$$
\operatorname{Re} Y=\frac{1}{R_{s}}
$$

Из представленного анализа видно, что при низких частотах проводимость определяется в основном сопротивлением контактов $R_{c}$ и от частоты не зависит. Аналогично при высоких частотах проводимость ограничивается сопротивлением образца $R_{s}$. Однако в промежуточном интервале частот проводимость имеет отличный от постоянной характер, а именно зависит от частоты квадратично.

Частотные зависимости проводимости, определяемой как

$$
\sigma=\frac{l}{S} \operatorname{Re} Y,
$$

где $l$ - расстояние между контактами, $S$ - площадь под контактами (в случае планарной конфигурации контактов - произведение длины контактов на толщину слоя ПК), для двух конфигураций контактов представлены на рис. 5. В случае проводимости перепендикулярно поверхности слоя на частотной зависимости наблюдаются два участка. На первом участке проводимость практически не зависит от частоты во всем интервале исследованных температур. При больших частотах наблюдается второй участок, характеризуемый ростом проводимости с частотой по закону близкому к квадратичному. Таким образом, здесь наблюдаются два характерных участка в полном соответствии с представленной эквивалентной схемой и приведенным анализом. В случае проводимости вдоль поверхности слоя наблюдается всего один участок, на котором проводимость практически не зависит от частоты (имеется очень слабая зависимость, близкая к степенной, с показателем степени меньше 0.1). Следует отметить, что отсутствие зависимости проводимости от частоты характерно для переноса по делокализованным состояниям [21-23]. Как уже отмечалось, в случае микропористого кремния предполагают, как правило, прыжковый механизм переноса носителей заряда между локализованными состояниями нанокристаллов. В случае же исследуемого мезопрористого кремния со средним размером нанокристаллов $\sim 10-100$ нм квантоворазмерный эффект не столь значительный, поэтому можно считать, что энергетическая зонная диаграмма для кремниевого нанокристалла такая же, как и для объемного кремния. В этом случае перенос носителей заряда (дырок) может происходить по делокализованным состояниям валентной зоны. При этом, в отличие от переноса в объемном кремнии, дыркам приходится преодолевать потенциальные барьеры, существующие на границах нанокристаллов, а также между пористым кремнием с подложкой и с Al-контактом.

\section{4. Основные результаты и выводы}

Таким образом, проведено сравнение проводимости мезо-ПК при переносе носителей заряда вдоль поверхности образца (перпендикулярно кремниевым колоннам) и перпендикулярно поверхности образца (вдоль кремниевых колонн). Обнаружена нелинейная зависимость силы тока в слоях ПК от приложенного напряжения для двух используемых в работе направлений электрического транспорта. Нелинейная зависимость силы тока от напряжения может свидетельствовать о наличии потенциальных барьеров в исследованных структурах, которые могут существовать как на границах образца с электрическими контактами, так и на границах кремниевых нанокристаллов. Из анализа температурных и частотных зависимостей проводимости сделан вывод о различных механизмах переноса носителей заряда в случаях планарной проводимости и проводимости поперек слоя. Предложена эквивалентная схема замещения, учитывающая сопротивление и емкость существующих в структуре потенциальных барьеров. Именно наличие потенциальных барьеров (различных для различной геометрии электрических контактов) определяет анизотропию проводимости мезо-ПК для различных направлений переноса носителей заряда.

\section{Финансирование работы}

Проведены в рамках тематик, разрабатываемых в Московском автомобильно-дорожном государственном техническом университете.

\section{Конфликт интересов}

Авторы заявляют, что у них нет конфликта интересов. 


\section{Список литературы}

[1] F. Koch, V. Petrova-Koch. J. Non-Cryst. Sol., 198-200, 840 (1996).

[2] S. Tiwari, F. Rana, H. Hanafi, A. Hartstein, E.F. Crabbe, K. Chan. Appl. Phys. Lett., 68, 1377 (1996).

[3] A.G. Gullis, L.T. Canham, P.D. Calcott. J. Appl. Phys. Lett., 82, 909 (1997).

[4] M. Chiesa, G. Amato, L. Boarino, E. Garrone, F. Geobaldo, E. Giamello Angew. Chem. Int. Ed., 42, 5032 (2003).

[5] M.T. Kelly, J.K.M. Chun, A.B. Bocarsly. Appl. Phys. Lett., 64, 1693 (2012).

[6] Е.А. Гостева, В.В. Старков, Ю.Н. Пархоменко, М.О. Ках, И.А. Иве. Альтернативная энергетика и экология, 231233, 1 (2017).

[7] Z. Huang, N. Geyer, P. Werner, J. de Boor, U. Gosele. Adv. Mater., 23, 285 (2011).

[8] M. Ben-Chorin, F. Möller, F. Koch. Phys. Rev. B, 49, 2981 (1994).

[9] П.А. Форш, М.Н. Мартышов, А.П. Латышева, А.С. Воронцов, В.Ю. Тимошенко, П.К. Кашкаров. ЖЭТФ, 134, 1195 (2008).

[10] Е.А. Агафонова, М.Н. Мартышов, П.А. Форш, В.Ю. Тимошенко, П.К. Кашкаров. ФТП, 44, 367 (2010).

[11] D. Stroud. Phys. Rev. B, 12, 3368 (1975).

[12] M.N. Martyshov, P.A. Forsh, V.Yu. Timoshenko, P.K. Kashkarov. J. Nanoelectron. Optoelectron., 4, 134 (2009).

[13] P.A. Forsh, M.N. Martyshov, V.Yu. Timoshenko, P.K. Kashkarov. Phys. Status Solidi C, 4, 1981 (2007).

[14] П.А. Форш, Л.А. Осминкина, В.Ю. Тимошенко, П.К. Кашкаров. ФТП, 38, 626 (2004).

[15] P.A. Forsh, L.A. Osminkina, D.M. Zhigunov, V.Yu. Timoshenko, P.K. Kashkarov. Phys. Status Solidi C, 2, 3404 (2005).

[16] М. Бродски. Аморфные полупроводники (М., Мир, 1982).

[17] Е.А. Форш, А.В. Марикуца, М.Н. Мартышов, П.А. Форш, М.Н. Румянцева, А.М. Гаськов, П.К. Кашкаров. ЖЭТФ, 138, 738 (2010).

[18] E.A. Forsh, A.V. Marikutsa, M.N. Martyshov, P.A. Forsh, M.N. Rumyantseva, A.M. Gaskov, P.K. Kashkarov. Thin Sol. Films, 558, 320 (2014).

[19] M.N. Martyshov, E.A. Forsh, A.V. Marikutsa, P.A. Forsh, M.N. Rumyantseva, A.M. Gaskov, P.K. Kashkarov. J. Nanoelectron. Optoelectron., 6, 452 (2011).

[20] Е.А. Форш, А.В. Марикуца, М.Н. Мартышов, П.А. Форш, М.Н. Румянцева, А.М. Гаськов, П.К. Кашкаров. Вестн. РГРТУ, 42, 98 (2012).

[21] И.П. Звягин. Кинетические явления в неупорядоченных полупроводниках (М., МГУ, 1984).

[22] Е.А. Форш, А.В. Марикуца, М.Н. Мартышов, П.А. Форш, М.Н. Румянцева, А.М. Гаськов, П.К. Кашкаров. Российские нанотехнологии, 7, 87 (2012).

[23] E.A. Forsh, A.M. Abakumov, V.B. Zaytsev, E.A. Konstantinova, P.A. Forsh, M.N. Rumyantseva, A.M. Gaskov, P.K. Kashkarov. Thin Sol. Films, 595, 25 (2015).

Редактор Г.А. Оганесян

\section{Dependence of the porous silicon conductivity on the carrier transport direction}

\author{
E.A. Guseva, E.A. Forsh \\ Moscow Automobile and \\ Road Construction State Technical University, \\ 125319 Moscow, Russia
}

Abstract We study the carrier transport mechanisms in the layers of mesoporous silicon for carrier transport along the layer surface (perpendicular to silicon columns) and perpendicular to the layer surface (along silicon columns). It is established that the conductivity measured along the layer surface is much lower than the conductivity measured perpendicular to the surface. The analysis of the temperature and frequency dependences of the conductivity lead to a conclusion that there are various carrier transport mechanisms in the cases considered. 